"The Mexican people are extremely confiding in their natural disposition, and at the same time they must be entirely satisfied regarding the sincerity of people who are strangers before complete confidence can be secured. In other words, they are very sagacious and discreet, making it necessary for physicians locating in any part of their republic to so conduct themselves that the poor as well as the rich may haveno cause to question their good intentions. In all the cities and larger towns may be found a suffeient number of native physicians to meet every ordinary demand. Many of these physicians are very scholarly and in every way competent to treat suc cessfully the diseases prevalent in that country. The require ments in their colleges are far in advance of American colleges, so far as the number of years of attendance is concerned. There is, however, an inexplicable fascination which takes possession of the people of that country in favor of foreign physicians, who have established a reputation for unusual skill, both in the practice of medicine and surgery. There has been a very serious prejudice on the part of the more educated against American physicians, but it is rapidly disappear ing, the result of the marked advancement on the part of our medical colleges in the past few years.'

The foregoing does not sound much like the "bear" Dr. Cerna would make you believe that I am. In the editorial, written before I saw Dr. Cerna's correspondence, and which will be published next week, I have the following to say :

"Dr. Milo Buel Ward of Topeka has received the appoint. ment by both the American and Mexican authorities of the Pan-American Medical Congress, of vice-president for Kansas, and has been furnished a liberal supply of literature to be distributed to any who desire to contribute a paper or attend the meeting, which will be held in the City of Mexico, November 16 to 19 , of this year. This literature includes special and genand regulations and appointment blanks, and will be of value and interest to all who intend to contribute or attend the meet ing. Dr. Ward will gladly supply these papers to all who desire them. This Congress will be a meeting of medical men of great renown from all parts of America and should be attended by every lover of his profession who can possibly go. The extremely polite and ever courteous Mexican insures to all who attend this great meeting a most delightful entertainment and an ever to be remembered pleasant occasion. No one can appreciate the painstaking courtesy of the Mexican people and their ability to make the stay of their friends pleasant and highly enjoyable, unless they visit that country and learn these facts from personal intercourse with them.

"There is no doubt whatever but the second Pan-American Medical Congress will be one of the most enjoyable and profitable meetings of the medical profession which has ever been held on this continent. Kansis should certainly have a liberal number of representatives at this meeting, and the Kansas Medical Journal urges the members of the profession throughout the State to at once notify Dr. Ward if they will furnish a paper or attend the meeting. It is desirous on the part of the General Executive Committee that all who are planning to go shall notify them through their local vice-president, in order that the Executive Committee in Mexico may plan to entertain their visitors. Let us again urge our readers to act promptly and decisively regarding this important matter, that our great State with its large number of prominent and active workers in the medical profession may have honorable representation at the second Pan-American Medical Congress."

No further reply to the unkind accusations of David Cerna, M.D., Ph.D., seems to me necessary. I am very fond of that country and admire the intelligent, educated Mexican very much and expect to attend the Congress, and feel assured that my time will be pleasantly and profitably spent, and that all the members of the profession who can find it possible to attend will be repaid for the time and money spent. Respectfully,

\section{Location of Journal.}

Chicago, Ill., July 1, 1896.

To the Editor:-I wish to change my vote to Washington, D. C., for the reason that, having maturely considered the subject, I am of impression that the JourNaL would gain a great deal by being published where its editorial rooms might be in close proximity to the Army Medical Museum, the great Army Medical Library, and the Smithsonian Institution. Financially, as I notice from the advertising columns, the principal support of the Journal comes from east of the Alleghanies, I do not see that the Association would be any worse off; beside that, the editor might have the advantage for the Asso. cIATION of the bright writers of the many scientific departments of the Government, in addition to those now upon the staff ; beside that, the power and influence of the Association in the matter of medical legislation would be very much greater with the Jourval published at the Capitol, where copies could be sent to members of committees of the House and of the Senate. It seems probable that but a short time will elapse before the Association will be compelled to have a standing committee on Congressional bills, like the British Medical Association, which now has a standing committee on Parliamentary bills. It must be obvious that in the neutral ground of the Capitol the Journal could develop its greatest strength easier and more conspicuously than in any other city. As it can never be a local journal owing to its very nature, and as it is not in competition with local journals, it is all the more necessary that a neutral place of publication be selected. For these reasons, I wish my vote changed from Chicago to Washington.

E. J. Doering, M.D.

\section{Apply the Baconian Method.}

Denver, Colo., July 3, 1896.

To the Editor:-In the name of scientific medicine I feel it to be a duty to protest against the promulgation of such ideas as those advanced under the heading "Lycopersicum Cardiopathia" in the issue of the Journal for June 27. In this article three pages of theory are offered us without, so far as I am able to find by careful examination, any facts whatever as a basis. In the first place, the substance which produces such dire results, acidum lycopersicum, is not mentioned by either Gould, Dunglison, Fowne, Roscoe and Schorlemmer or any authority that I have consulted, while the article itself gives no further proof of its existence than the bare statement that it has been found in the tomato.

I submit that a single case, carefully observed and recorded, of any disturbance of any kind, if such ever existed, from the ingestion of this universally used article of food, would be worth infinitely more than pages of mere theoretic twaddle as to the effect of the acid with the long name. I doubt if any ill effects have ever been noted, by any competent observer, from the use of the tomato, other than may be accounted for by ordinary indigestion, fermentation, or personal idiosyncrasy. It is time for some one to call attention most vigorously to the point that we will make of medicine more nearly an exact science only by collecting facts and reasoning from them, or, in other words, by following the methods pointed out by Bacon, adherence to which methods has been the sine qua non of progress in all branches of scientific knowledge since his time.

If I speak warmly, it is only because I feel that the occasion calls for vigorous denunciation of such pseudo-science.

Yours very truly,

J. N. HALL, M.D.

Multum in Parvo.-Dr. J. P. Crozer Griffith reports a case of varicella gangrenosa, diphtheria, rubeola and varicella existing at the same time in a child aged 22 months, admitted to the Children's hospital of Philadelphia.-Med. and Surg. Reporter, June 27, 1896. 